\title{
A systematic review on the influence of fear of falling on quality of life in older people: is there a role for falls?
}

This article was published in the following Dove Press journal:

Clinical Interventions in Aging

\author{
Daniel Schoene ${ }^{1,2}$ \\ Claudia Heller' \\ Yan N Aung' \\ Cornel C Sieber ${ }^{1,3}$ \\ Wolfgang Kemmler ${ }^{2}$ \\ Ellen Freiberger' \\ 'Institute for Biomedicine of Aging, \\ Friedrich-Alexander University Erlangen- \\ Nürnberg, Nuremberg, Germany; \\ ${ }^{2}$ Institute of Medical Physics, Friedrich- \\ Alexander University Erlangen-Nürnberg, \\ Erlangen, Germany; ${ }^{3}$ Department of \\ General Internal and Geriatric Medicine, \\ Hospital of the Order of St. John of God \\ Regensburg, Regensburg, Germany
}

Correspondence: Daniel Schoene Institute for Biomedicine of Aging, Friedrich-Alexander University ErlangenNürnberg, Nuremberg, Kobergerstr. 60, Nuremberg 90408, Germany Email daniel.schoene@fau.de

\begin{abstract}
Maintaining or improving quality of life $(\mathrm{QoL})$ is a key outcome of clinical interventions in older people. Fear of falling (FoF) is associated with activity restriction as well as with poorer physical and cognitive functions and may be an important contributor to a diminished QoL. The objectives of this systematic review were to determine i) the effect of FoF on QoL in older people, ii) whether the association between these two constructs depends on the use of specific conceptualizations and measurement instruments, and iii) the role of fall events as mediating factor in this relationship. Four electronic databases (PubMed, EMBASE, CINAHL, and Cochrane Library) were searched from their inceptions to February 2018. Thirty mostly cross-sectional studies in nearly 30.000 people (weighted mean age 75.6 years ( $\mathrm{SD}=6.1$ ); $73 \%$ women) were included. FoF was associated with QoL in most studies, and this association appeared to be independent of the conceptualization of FoF. Moreover, this relationship was independent of falls people experienced which seemed to have a lower impact. FoF should be considered not only as by-product of falls and targeted interventions in parts different from those to reduce falls are likely required. Studies are needed showing that reducing FoF will lead to increased QoL.
\end{abstract}

Keywords: fear of falling, falls efficacy, quality of life, accidental falls, aged, function

\section{Introduction}

Falls in older adults are frequent events with severe consequences for the individual and high associated costs for the health care systems. Apart from physical injury, such as bone fractures and traumatic brain injuries, psychological consequences such as fear associated with falls might be just as detrimental for the individual in the long term. Together they may lead to disability, need for care, and loss of independence, greatly affecting one's quality of life (QoL). A great variability in the prevalence of fear of falling (FoF) has been reported, ranging from 3\% to as high as $92 \%$ of the community-dwelling elderly fallers. ${ }^{1,2}$ First reported as fear-related "post-fall syndrome" affecting about one-third of older people admitted to hospital after a fall, ${ }^{3}$ today, this fear is no longer considered a "post-fall syndrome". It has been shown that in more than $50 \%$ of the people with no prior fall experience, FoF exists. ${ }^{2,4-7}$ Conceptually, there are two different approaches to define and operationalize FoF. First, there is the definition focusing on the fear itself by measuring the fearful anticipation of future falls, for instance by using one-item questions ("At the present time, are you very fearful, somewhat fearful, or not fearful that you may fall?"). The second definition relates to Bandura's theory of self-efficacy ${ }^{8}$ and measures the 
construct of fall-related efficacy, which is the (loss of) confidence in one's abilities during certain tasks of daily life. Examples for instruments to assess fall-related efficacy are the Fall-Efficacy Scale (FES) by Tinetti ${ }^{9}$ and the Activities-specific Balance Confidence Scale by Powell \& Myers. ${ }^{10}$ FoF is associated with poorer performance in physical, mobility, and cognitive tests. ${ }^{11,12}$ One major consequence of this fear is the subsequent restriction of activities leading into a downward spiral of inactivity, deconditioning, loss of confidence, and further increased fall risk. ${ }^{13,14}$ Hence, it is not surprising that FoF has been found to be associated with frailty in older adults. ${ }^{15}$ The restriction of activities caused by fear-avoidance behavior also affects participation in social activities, a factor underlying reduced QoL. ${ }^{16,17}$

Quality of life is a broad, subjective, and complex construct that depends on cultural and social circumstances. Gerok and Brandstädter describe QoL and a long life without severe functional limitations as the key components of successful aging. ${ }^{18}$ Changes in physical, mental, and functional dimensions during the aging process caused by illness, multimorbidity, and cognitive impairments affect QoL as do significant life transitions, such as retirement and the loss of important life partners. ${ }^{19}$ Thus, the construct of QoL consists of physical, social, and emotional dimensions ${ }^{19,20}$ and includes the satisfaction of basic needs as well as the sensation of happiness and fulfillment. ${ }^{21}$ Strongly related to the construct of QoL and mostly used in research is the construct of health-related quality of life (HRQoL). As for QoL, there is no universal definition of HRQoL. ${ }^{22}$ Similarly to QoL, it is a multidimensional concept that focuses on the impact health has on QoL, based on the individual's perception of well-being and functioning. ${ }^{20},{ }^{22}-{ }^{24}$ In this article, we will refer to both concepts as QoL.

According to the World Health Organization, in addition to an increased lifespan, the main goal of health care is to ensure "adding life to years" 25 in recognition of the significance of high QoL for people. Although underlying medical conditions and functional performance need to be targeted, patientreported outcomes, such as QoL are more and more important in health care systems that move beyond survival. ${ }^{26}$ Thus, in older people with multiple chronic conditions and functional limitations, main aim should be maintaining or improving QoL. ${ }^{27,28}$ The demographics worldwide are changing rapidly toward aging societies. Therefore, the problem of FoF and falls and their impact on QoL is going to increase. However, to our knowledge, there has been no systematic analysis of the influence of FoF on QoL, including the clinically relevant issues addressed above (conceptualizations and measurement instruments for FoF/QoL and the mediating effect of actual fall events). We, therefore, conducted a systematic literature review to determine the impact of FoF on QoL. Specifically, we attempted to answer the following questions: 1) What is the effect of FoF on QoL? 2) Does the association depend on the operationalization of FoF or QoL? 3) Is there a mediating effect of falls on the effect of FoF on QoL?

\section{Methods}

\section{Literature search strategy}

Four electronic databases (PubMed, EMBASE, CINAHL, Cochrane Library) were searched for articles published from their inceptions to 12th of February 2018, with an initial search on 21 May 2015 and an update in February 2018. We applied a combined search of Medical Subject Headings (MeSH) and keywords related to fear ("fear of falling", anxiety, "self-efficacy", "self efficacy", "self confidence", "falls-efficacy", "falls efficacy", "balance confidence", "fallrelated efficacy", "activity restriction"), older age (Aged, "older adults", "older persons", elderly, senior*), and QoL ("quality of life", QoL, HRQoL, "well-being"). If possible (PubMed, EMBASE, CINAHL), the search was limited to English language only. The Cochrane database was limited to "Trials". PubMed and CINAHL searches were further specified by excluding articles with diseases/medical conditions specified in the title (eg, Parkinson's Disease, stroke) and those that stated "review" or "randomized controlled" in the title field. Reference lists of included studies and review articles were also searched for relevant articles.

\section{Eligibility criteria}

Articles were included when they reported on studies fulfilling the following criteria: i) cohort, cross-sectional (including baseline data from intervention studies) or case-control study design; ii) minumum age of participants 60 years or mean age 65 years and older; iii) included measures of FoF and QoL which were put into relation to each other. Studies were excluded if they investigated disease-specific populations and were not published peer-reviewed articles (no abstracts or theses) in languages other than English.

\section{Screening process, data extraction, and risk assessment}

In a first step, the initial screening of titles and abstracts was performed. Subsequently, the assessment for eligibility of 
retrieved full texts was conducted. A standardized, prepiloted form was used to extract data from included studies. Extracted information included: study design; sample size; sample characteristics (age, gender, ethnicity, setting, health (conditions, co-morbidity, medications), falls, use of walking aids); instrument for assessing FoF; instrument for assessing QoL; prevalence/incidence of FoF; association between FoF and QoL. The 'Quality Assessment Tool for Observational Cohort and Cross-Sectional Studies' was used to critically appraise the risk of bias of included studies. ${ }^{29}$ Fourteen items were rated as 'yes', 'no', or 'other' (cannot be determined, not applicable, not reported) with no use of an overall score. All above-mentioned processes were done independently by two reviewers. Any disagreement was solved through discussion with a third reviewer.

Due to the large heterogeneity of instruments used for both constructs and differences in investigated populations we refrained from performing meta-analysis.

\section{Results}

\section{Description of included studies}

Thirty articles were included in this systematic review. Figure 1 describes the process of identification of included studies. A variety of study designs were applied, including cross-sectional studies, cohort studies, and pre-post group design studies. However, for the purpose of this review, all but one $\operatorname{study}^{30}$ used a cross-sectional design. Overall,
29,029 individuals were included with sample sizes ranging widely between $32^{31}$ and 11,802 participants. ${ }^{32}$

Table 1 displays the characteristics of included studies. Most participants resided in the community. Exceptions were few studies recruiting participants from nursing homes, ${ }^{33-35}$ retirement villages/senior housing, ${ }^{4,36}$ emergency department, ${ }^{37}$ and day services. ${ }^{38}$

Apart from one study that included people from 58 to 96 years (mean age 78), ${ }^{39}$ all studies had participants' minimum ages of 60 years. Thirteen publications included only participants of 65 years and older ${ }^{15,30,31,37,40-48}$ and 6 studies only adults above 70 years..$^{32,33,35,49-51}$ Overall, the weighted mean age of 25 studies reporting on this outcome was 75.6 years $(S D=6.1$ (22 studies)).

The overall weighed proportion of women was $73 \%$, ranging from $40 \%$ to $84 \%$. Four studies exclusively recruited women. ${ }^{30,32,35,50}$

Study populations consisted of numerous cultures from all inhabited continents and 16 countries, ie, Nigeria, ${ }^{40}$ Brasil, $^{48}$ Canada, ${ }^{30,36}$ USA $^{4,15,39,49,52}$ China/HK, ${ }^{34,47}$ Iran, ${ }^{53}$ Japan, ${ }^{35,38}$ Taiwan, ${ }^{41-44,46}$ Thailand, ${ }^{54}$ Vietnam, ${ }^{55}$ New Zealand/Australia, ${ }^{51}$ Finland, ${ }^{50}$ Germany, ${ }^{33,43}$ Greece, ${ }^{56}$ Turkey, ${ }^{31,37}$ and UK. ${ }^{32,45,57}$

Health status of participants differed significantly across studies, from healthy to functionally impaired and frail covering a wide spectrum of fall risk. Generally, participants did not suffer from degenerative diseases and

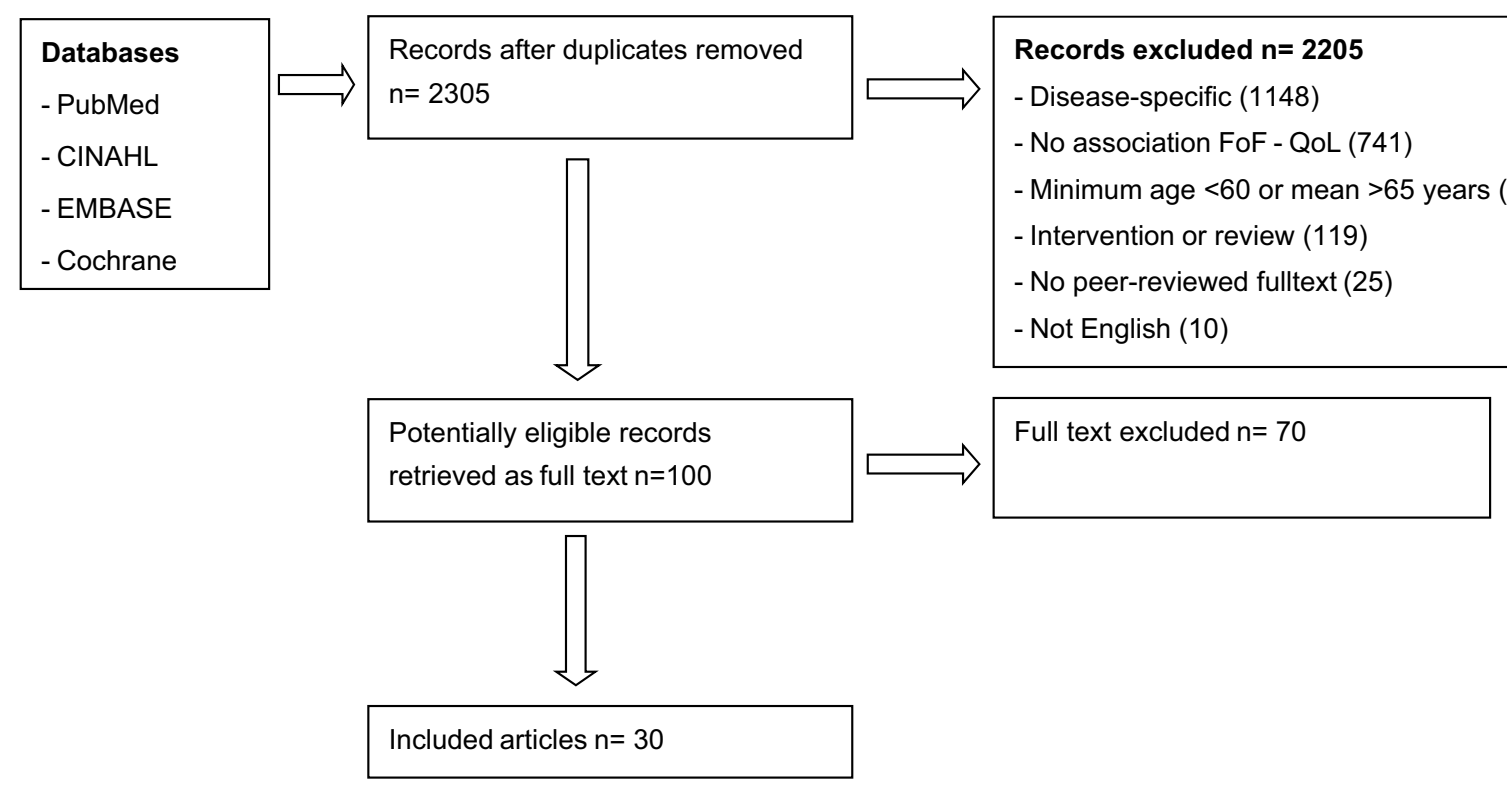

Figure I Flowchart of study selection process.

Abbreviations: FoF, fear of falling; QoL, quality of life. 


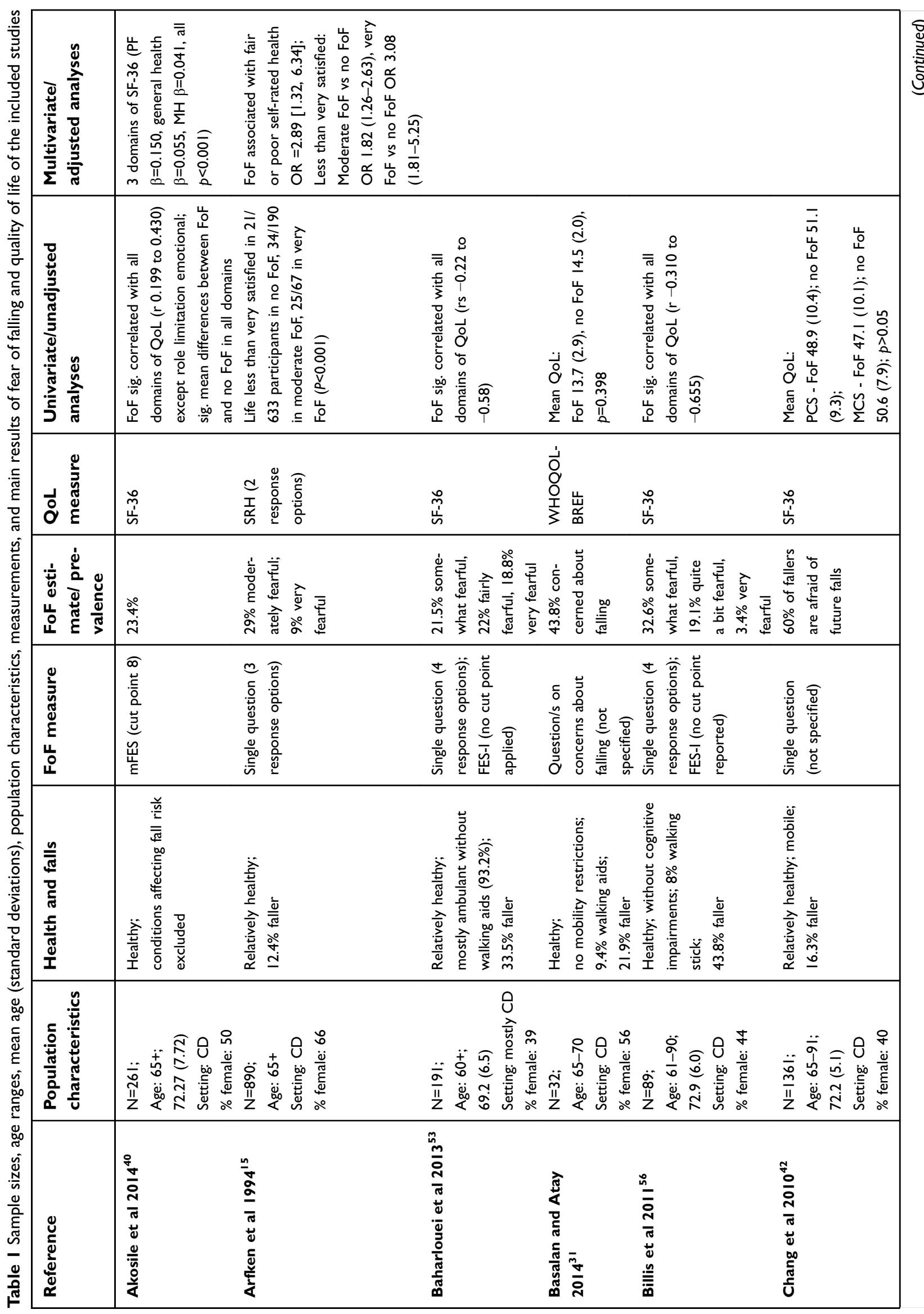




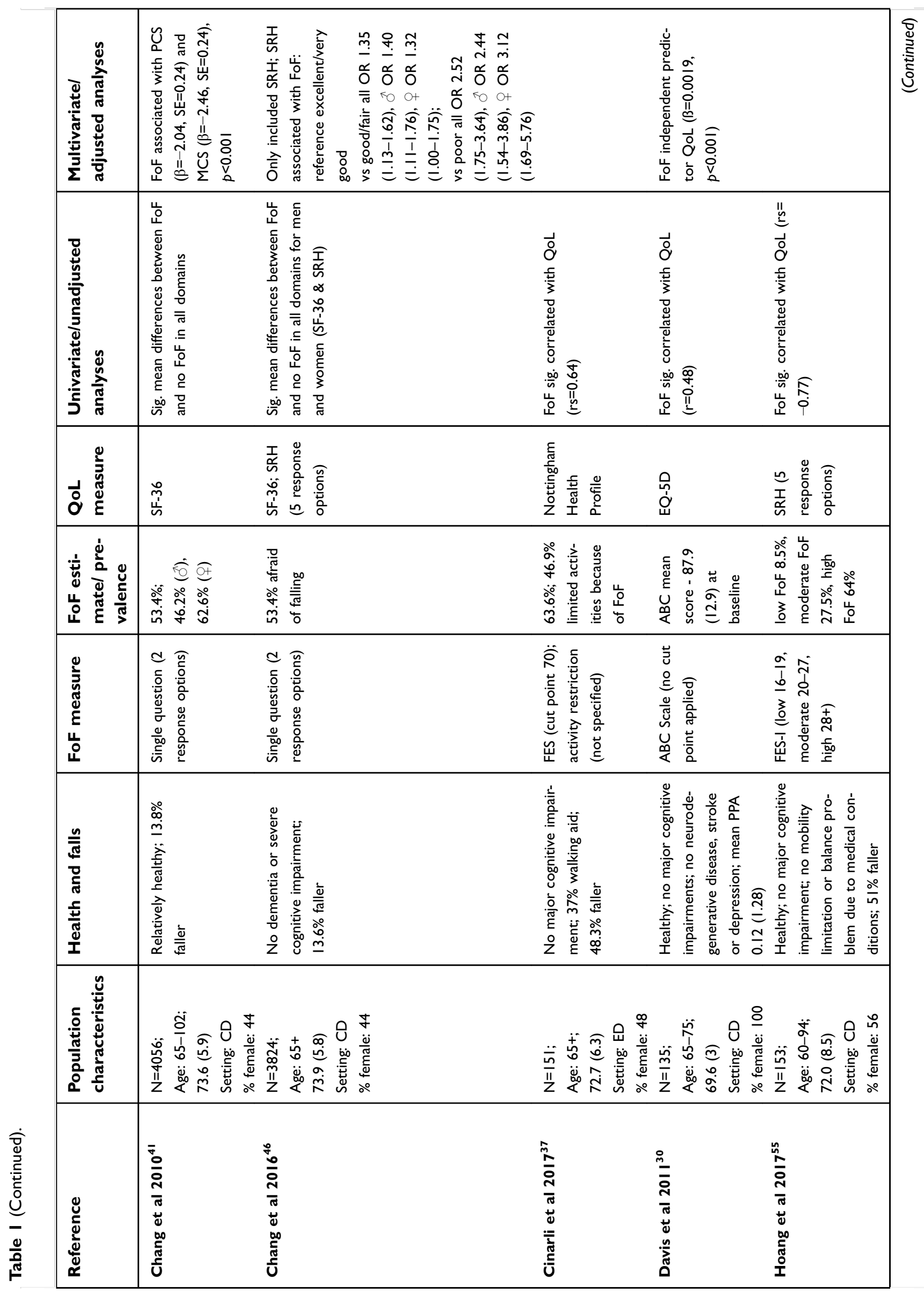




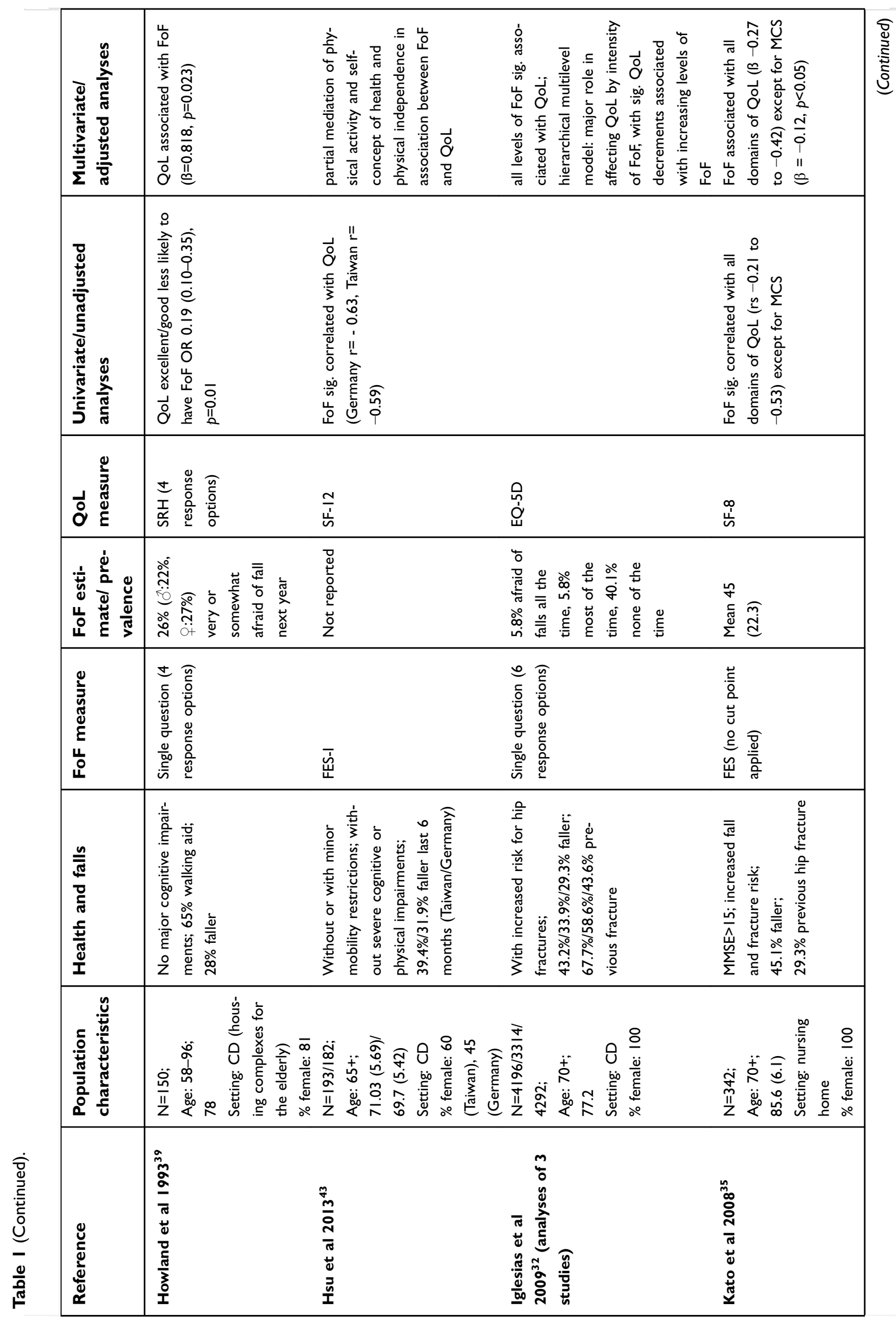




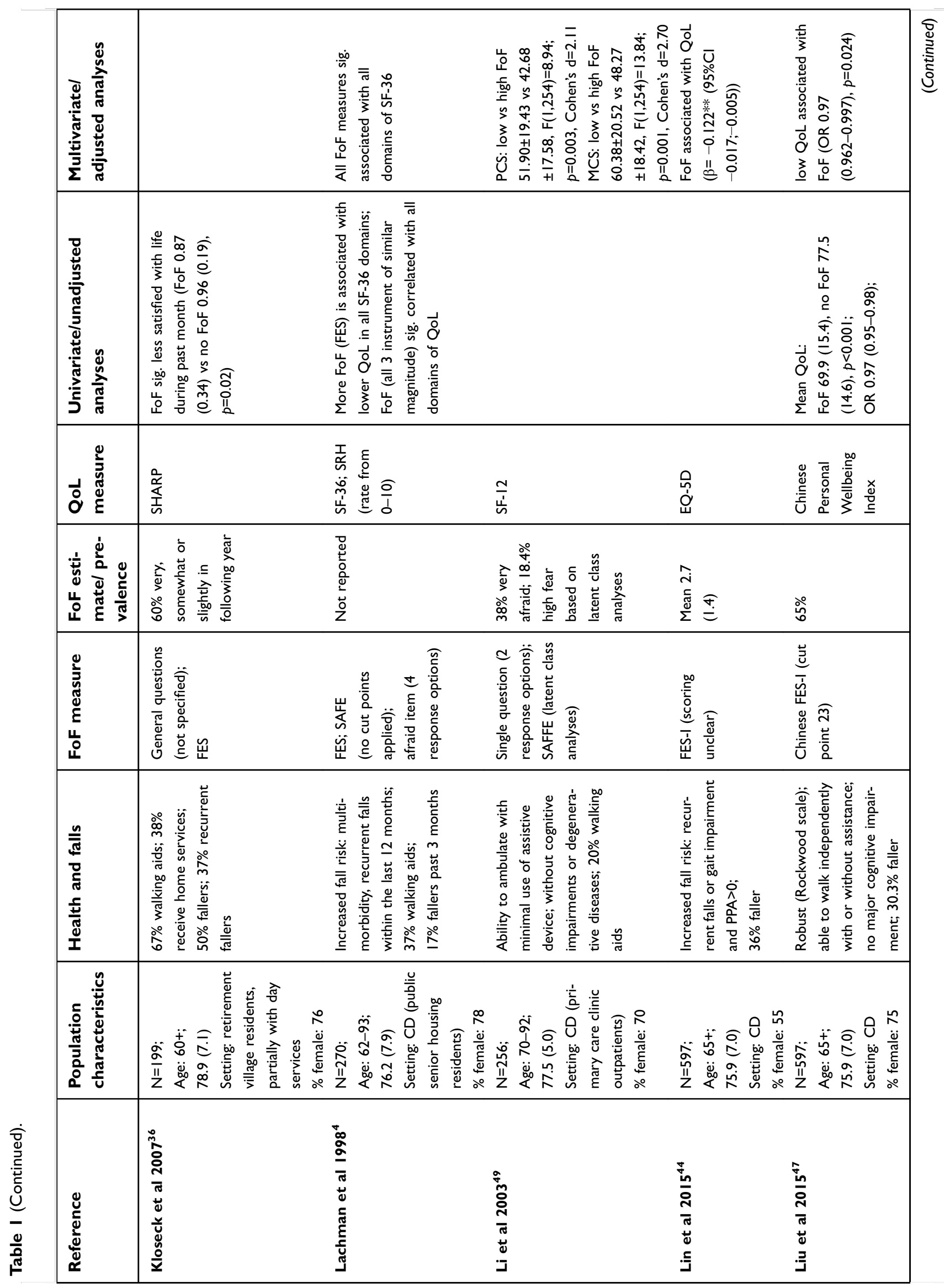




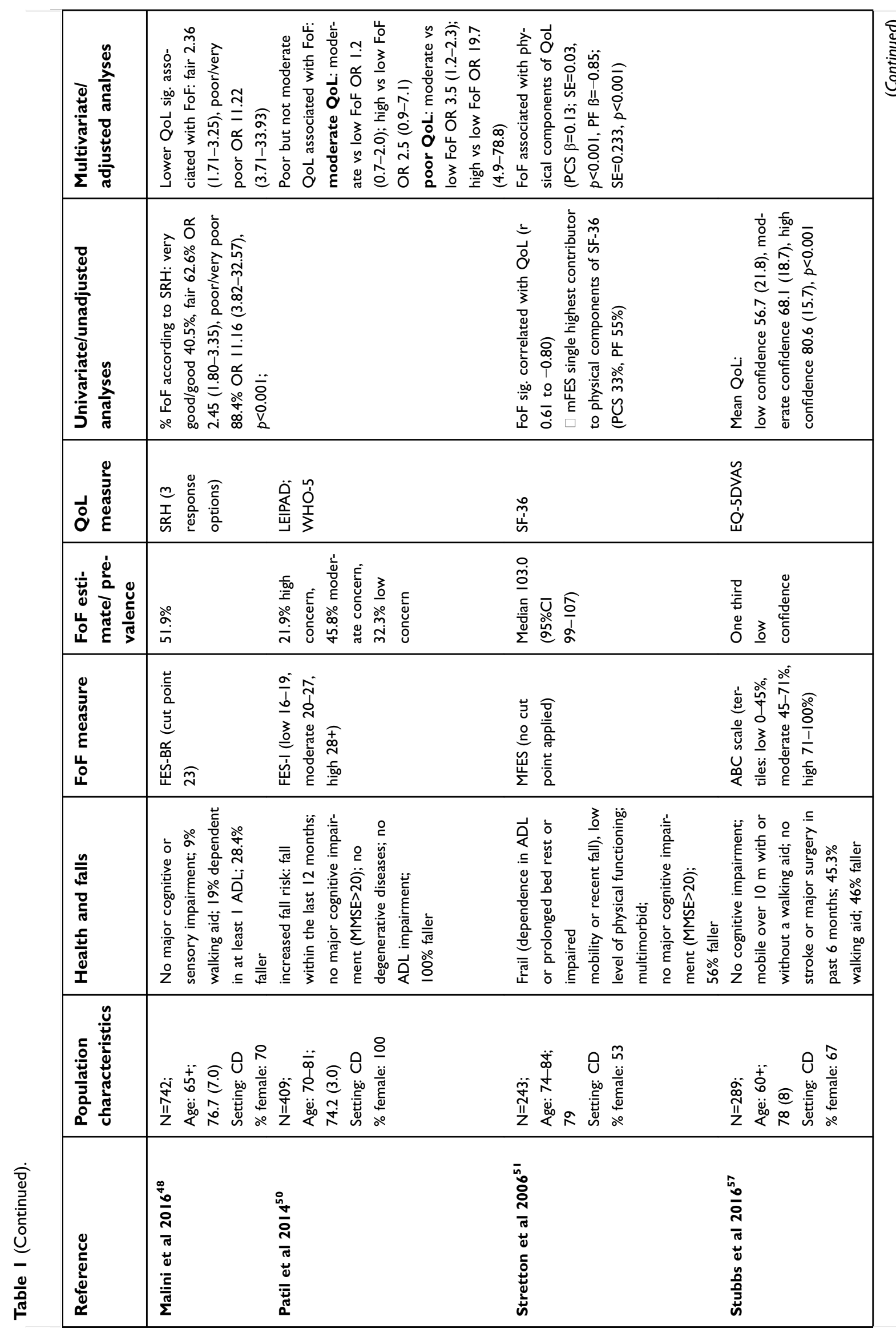




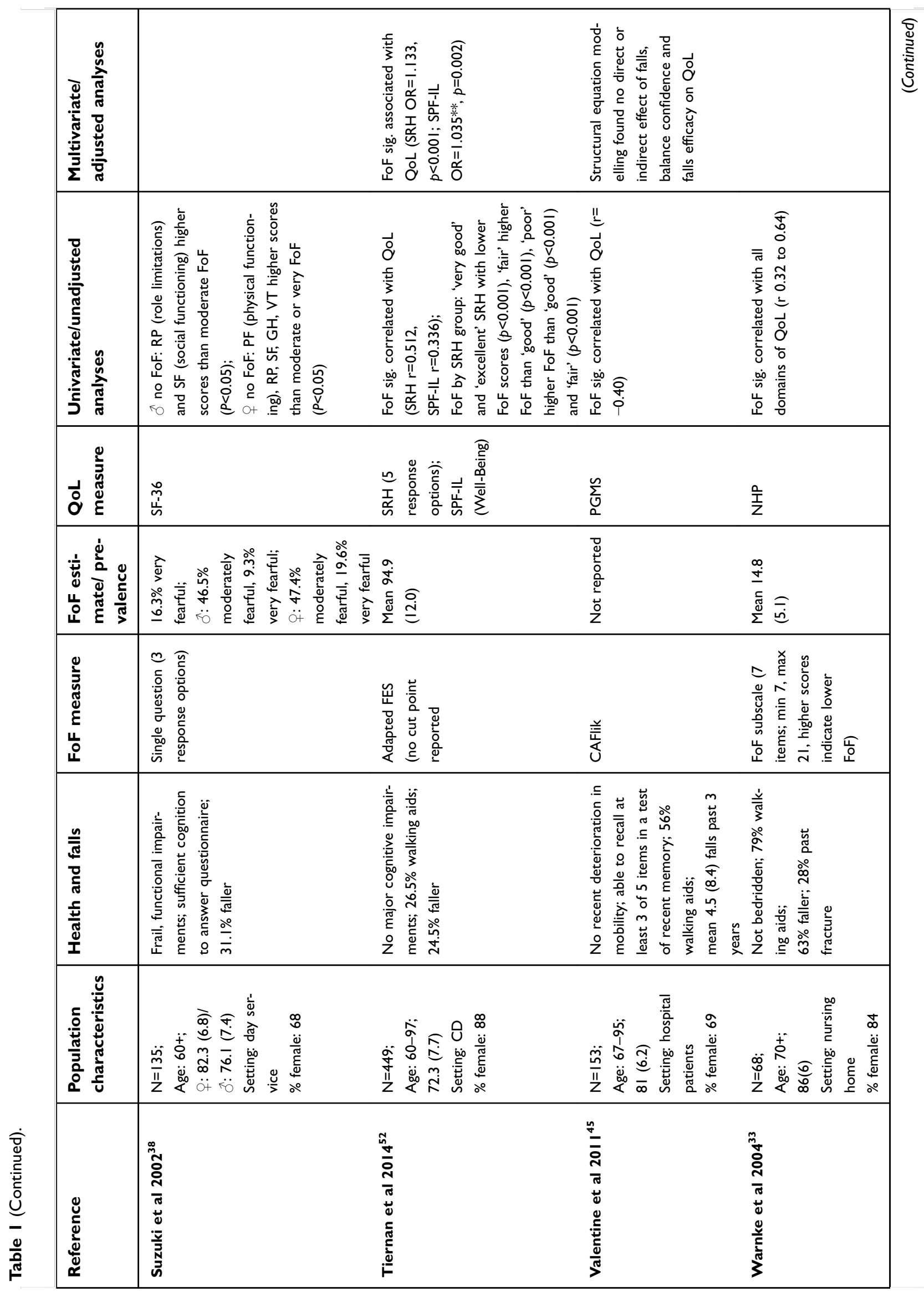




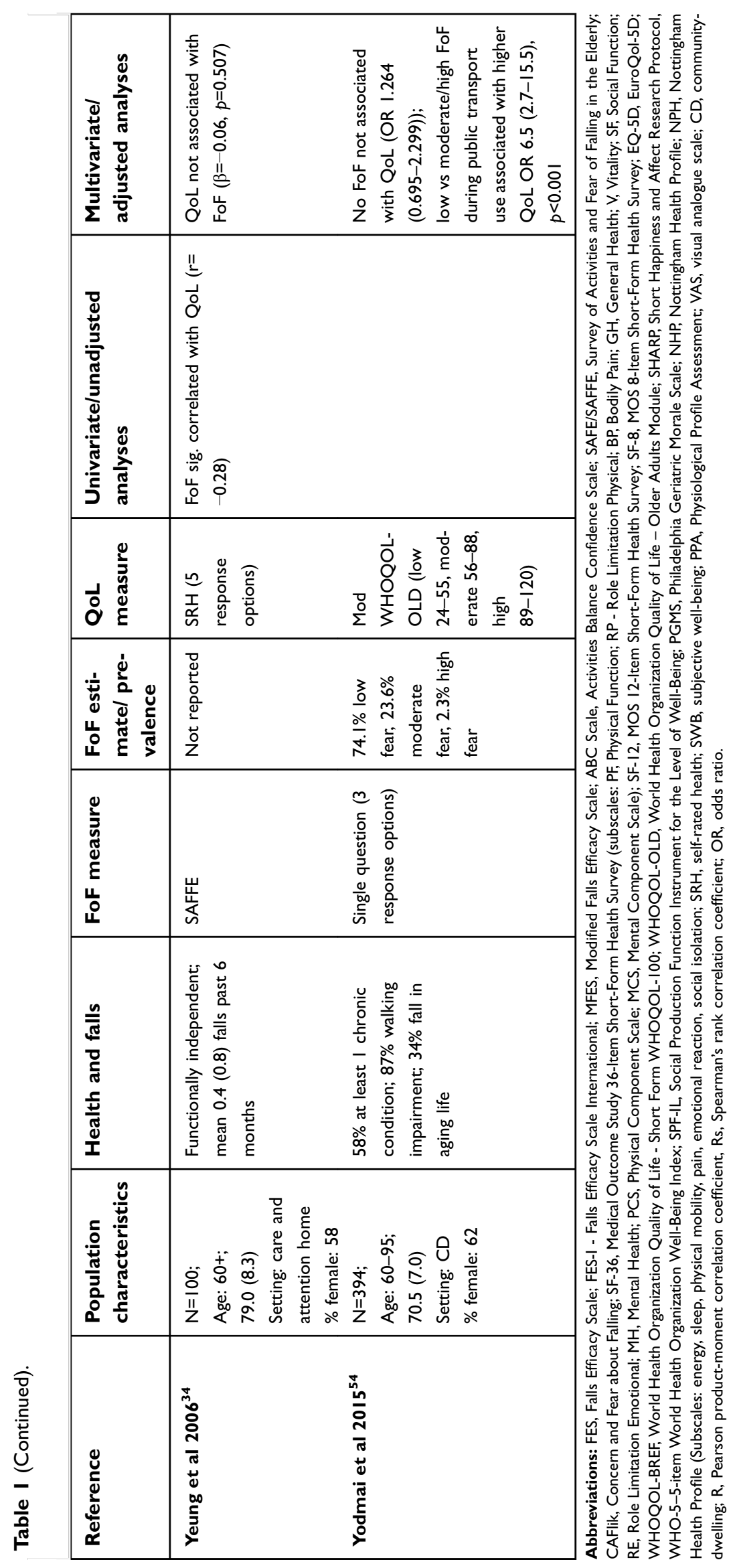


were cognitively functioning on a sufficient level. Need of walking aids was used as marker for function that was reported by a majority of studies and ranged from $0 \%{ }^{53}$ to $79 \%$. ${ }^{33}$ Falls during the past year, when reported, ranged from $12.4 \%{ }^{15}$ to $100 \%{ }^{50}$ Several studies reported on previous fractures $32,33,35,48$ ranging from $3.9 \%$ to $68 \%$.

\section{Measurement instruments for FoF and QoL}

Most studies utilized standard FoF questionnaires related to self-efficacy including the FES and its variations (FES-I and MFES, translations) $)^{3,4,37,40,43,44,47,48,50-53,55,56}$ and the ABC scale. $^{30,57}$ The SAFE, measuring the activity restrictions due to FoF was used in three studies. ${ }^{4,34,49}$ Nine studies identified FoF with a single question; ${ }^{15,31,32,38,39,41,42,46,54}$ however, response options partially differed (dichotomized, 3-, 4-, 6-level scale). One study applied three questionnaires for different aspects of FoF (consequences of falling: CONSq; falls-efficacy measures - concern and fear about falling: CAFlik, balance confidence: CONbal). ${ }^{45}$ Another study developed an instrument that used ratings by nursing staff in combination with a newly developed QoL questionnaire in people with FoF consisting of three subscales, one of them being "fear of falling". 33

The evaluation of the participants' QoL was also administered by a wide range of standard instruments, the SF-36, $4,38,40-42,46,51,53,56 \quad$ SF- $12,{ }^{43,49}$ SF- $8,{ }^{35}$ EQ-5D, ${ }^{30,32,44}$ WHOQOL-BREF, ${ }^{31}$ modified WHO QOL-OLD, ${ }^{54}$ Short Happiness and Affect Research Protocol (SHARP), ${ }^{36}$ LEIPAD, ${ }^{50}$ WHO (Five) WellBeing Index (WHO-5), ${ }^{50}$ Social Production Function Instrument (SPF-IL), ${ }^{52}$ Nottingham Health Profile (NHP), ${ }^{33,37}$ Philadelphia Geriatric Morale Scale (PGMS), ${ }^{45}$ and Chinese Personal Wellbeing Index (CPWI). ${ }^{47}$ Eight studies used single questions related to self-rated health (SRH) status using a visual analog scale $^{57}$ or graded response options with dichotomized, ${ }^{15}$ three, ${ }^{48}$ four, ${ }^{39}$ and five categories. ${ }^{34,46,52,55}$

\section{Methodological quality assessment}

The methodological quality of included studies was largely homogeneous (Table 2). With the exception of one study, ${ }^{54}$ the population was clearly defined. However, in only half of the studies, the participation rate was clearly $50 \%$ or above, potentially affecting generalizability of results. For the questions of interest, all but one study were of cross-sectional design. ${ }^{30}$ However, also in the study by Davis et al, no temporal relationship between falls-related self-efficacy and QoL was investigated and thus forbidding any cause-effect relationship. ${ }^{30}$ Except for few studies for which scoring, or test-retest reliability were unclear, all studies used valid and reliable instruments for FoF and QoL. For the mediating effect of actual fall events on the relationship between FoF and QoL, none of the studies included exclusively these three measures and models were adjusted for different variables, mostly related to demographics and health. Small sample sizes likely impacted on the results in several studies. This was also due to most studies having had other primary objectives than the current review. None of the studies reported on blinding of outcome assessors for relevant outcomes.

\section{Prevalence/incidence of fear of falling}

From 30 articles, several did not provide data on prevalence, incidence, or point estimates with spread measures of FoF for their respective study samples. 4,34,43,45 Prevalence rates of remaining studies varied widely likely due to differences in sample characteristics and measurement properties (scoring, number of categories, wording). Participants without mobility restrictions or increased fall risk had the lowest FoF prevalence $(<30 \%)^{15,39,40,57}$ Higher prevalence rates of FoF were found in frail populations, ${ }^{38}$ increased with the number of experienced falls, ${ }^{36,50,57}$ was higher in people at increased risk of hip fractures $^{32}$ or in those with previous fall-related fractures, ${ }^{48}$ in individuals with chronic musculoskeletal pain $^{57}$ and in people requiring walking aids for ambulation. 4,39,53,57 $^{\text {Several studies reported higher levels }}$ of FoF in women. $4,36,38,39,41,46-48,53,55$

\section{What is the effect of FoF on QoL?}

Better QoL was consistently associated with lower levels of FoF. Comparison of means/ranks showed that people with less FoF rated their QoL better. ${ }^{31,36,41,42,46,47,49,52,57}$ When using multiple categories for FoF, this seems to be a linear relationship with higher levels of FoF being associated with poorer scores on QoL. ${ }^{15,32,38,48,50,52,57}$ Several studies reported moderate to strong correlations between FoF and QoL ( $\mathrm{r}=-0.47$ to -0.80$)$. $^{30,37,43,45,51,52,55}$ The relationship between FoF and QoL appears to be stronger for the physical than for the mental components of QoL. Comparing sub-scales of the SF-36 and its modified versions, highest correlations were observed for the physical function domain. 4,35,40,53,56 Beside the physical function domain, also other physical domains such as bodily 
Table 2 Rating of methodological quality of included studies using the 'Quality assessment tool for observational cohort and crosssectional studies'29

\begin{tabular}{|c|c|c|c|c|c|c|c|c|c|c|c|c|c|c|}
\hline & $\mathbf{I}$ & 2 & 3 & 4 & 5 & 6 & 7 & 8 & 9 & 10 & I I & 12 & 13 & 14 \\
\hline Akosile et al $2014^{40}$ & & Yes & NR & Yes & & No & No & No & Yes & NA & Yes & NR & NA & No \\
\hline Arfken et al $1994^{15}$ & & Yes & Yes & Yes & & No & No & No & Yes & NA & Yes & NR & NA & Yes \\
\hline Baharlouei et al $2013^{53}$ & & Yes & NR & Yes & & No & No & No & Yes & NA & Yes & NR & NA & No \\
\hline Basalan and Atay $2014^{31}$ & & Yes & No & Yes & & No & No & No & $C D$ & NA & Yes & NR & NA & No \\
\hline Billis et al $2011^{56}$ & & Yes & NR & Yes & & No & No & No & Yes & NA & Yes & NR & NA & No \\
\hline Chang, Yang and Chou $2010^{42}$ & & Yes & Yes & Yes & & No & No & No & $C D$ & NA & Yes & NR & NA & No \\
\hline Chang et al $2010^{41}$ & & Yes & Yes & Yes & & No & No & No & Yes & NA & Yes & NR & NA & Yes \\
\hline Chang et al $2016^{46}$ & & Yes & Yes & Yes & & No & No & NA & Yes & NA & Yes & NR & NA & Yes \\
\hline Cinarli et al $2017^{37}$ & & Yes & Yes & Yes & & No & No & Yes & Yes & NA & Yes & NR & NA & No \\
\hline Davis et al $2011^{30}$ & & Yes & Yes & Yes & & No & $C D$ & Yes & Yes & No & Yes & NR & Yes & No \\
\hline Hoang et al $2017^{55}$ & & Yes & NR & Yes & & No & No & Yes & Yes & NA & Yes & NR & NA & No \\
\hline Howland et al $1993^{39}$ & & Yes & Yes & Yes & & No & No & No & Yes & NA & Yes & NR & NA & Yes \\
\hline Hsu et al $2013^{43}$ & & Yes & NR & No & & No & No & Yes & Yes & NA & Yes & NR & NA & No \\
\hline Iglesias et al $2009^{32}$ & & Yes & No & No & & No & No & Yes & Yes & NA & Yes & NR & NA & Yes \\
\hline Kato et al $2008^{35}$ & & Yes & Yes & Yes & & No & No & Yes & Yes & NA & Yes & NR & NA & Yes \\
\hline Kloseck et al $2007^{36}$ & & Yes & No & Yes & & No & No & Yes & $C D$ & NA & Yes & NR & NA & Yes \\
\hline Lachman et al $1998^{4}$ & & Yes & Yes & Yes & & No & No & Yes & Yes & NA & Yes & NR & NA & Yes \\
\hline Li et al $2003^{49}$ & & Yes & $C D$ & Yes & & No & No & No & Yes & NA & Yes & NR & NA & No \\
\hline Lin et al $2015^{44}$ & & Yes & NR & Yes & & No & No & Yes & Yes & NA & Yes & NR & NA & No \\
\hline Liu et al $2015^{47}$ & & Yes & NR & Yes & & No & No & No & Yes & NA & Yes & NR & NA & Yes \\
\hline Malini et al $2016^{48}$ & & Yes & NR & Yes & & No & No & No & Yes & NA & Yes & NR & NA & Yes \\
\hline Patil et al $2014^{50}$ & & Yes & Yes & Yes & & No & No & Yes & Yes & NA & Yes & NR & NA & Yes \\
\hline Stretton et al $2006^{51}$ & & Yes & No & Yes & & No & No & Yes & Yes & NA & Yes & NR & NA & No \\
\hline Stubbs et al $2016^{57}$ & & Yes & Yes & Yes & & No & No & Yes & Yes & NA & Yes & NR & NA & No \\
\hline Suzuki et al $2002^{38}$ & & Yes & NR & Yes & & No & No & Yes & Yes & NA & Yes & NR & NA & No \\
\hline Tiernan et al $2014^{52}$ & & Yes & Yes & Yes & & No & No & Yes & $C D$ & NA & Yes & NR & NA & Yes \\
\hline Valentine et al $201 I^{45}$ & & Yes & Yes & Yes & & No & No & Yes & Yes & NA & Yes & NR & NA & Yes \\
\hline Warnke et al $2004^{33}$ & & Yes & Yes & Yes & & No & No & Yes & $C D$ & NA & Yes & NR & NA & No \\
\hline Yeung et al $2006^{34}$ & & Yes & Yes & Yes & & No & No & Yes & Yes & NA & Yes & NR & NA & Yes \\
\hline Yodmai et al $2015^{54}$ & & No & NR & Yes & & No & No & Yes & Yes & NA & Yes & NR & NA & Yes \\
\hline
\end{tabular}

Notes: I. Was the research question or objective in this paper clearly stated?; 2 . Was the study population clearly specified and defined?; 3 . Was the participation rate of eligible persons at least 50\%?; 4. Were all the subjects selected or recruited from the same or similar populations (including the same time period)? Were inclusion and exclusion criteria for being in the study prespecified and applied uniformly to all participants?; 5 . Was a sample size justification, power description, or variance and effect estimates provided?; 6. For the analyses in this paper, were the exposure(s) of interest measured prior to the outcome(s) being measured?; 7. Was the timeframe sufficient so that one could reasonably expect to see an association between exposure and outcome if it existed?; 8. For exposures that can vary in amount or level, did the study examine different levels of the exposure as related to the outcome (eg, categories of exposure, or exposure measured as continuous variable)?; 9 . Were the exposure measures (independent variables) clearly defined, valid, reliable, and implemented consistently across all study participants?; 10. Was the exposure(s) assessed more than once over time?; II. Were the outcome measures (dependent variables) clearly defined, valid, reliable, and implemented consistently across all study participants?; I2. Were the outcome assessors blinded to the exposure status of participants?; 13. Was loss to follow-up after baseline $20 \%$ or less?; 14. Were key potential confounding variables measured and adjusted statistically for their impact on the relationship between exposure(s) and outcome(s)? As in most studies had objectives differed to the question of this review, we decided Not to apply Items I and 5.

Abbreviations: CD, community dwelling; NR, not reported; NA, not applicable.

pain, ${ }^{15,35,40,46,56}$ general health perceptions, ${ }^{4,15,40,46,56}$ and physical role functioning ${ }^{15,35,46,56}$ were associated with FoF. Exceptions were studies that found similar associations with the mental health domain. ${ }^{46,56}$ One study demonstrated a moderate correlation between the social role functioning domain and FoF, measured with FES and SAFE in residents of public senior housing communities. ${ }^{4}$
Regression analyses showed that FoF is an independent predictor for QoL. ${ }^{15,30,32,39,41,44,46-48,50-52}$ Again, this relationship was stronger for the physical components of QoL. ${ }^{4,35,40,44,50}$ Stretton and colleagues ${ }^{51}$ reported that the MFES was the single highest contributor to SF-36 physical component summary score and the physical function domain in frail older adults. Moreover, FoF and QoL 
appeared to be more important for predicting each other than other basic variables such as age, gender, previous falls, and comorbidity. ${ }^{4,40,46,48,51}$ In contrast, Valentine and colleagues $^{45}$ using structural equation modeling found no direct effect of balance confidence or self-efficacy on the relationship between postural instability and QoL in a geriatric rehabilitation setting; however, they found a relationship between QoL and general anxiety. Yodmai and colleagues ${ }^{54}$ found no associations between FoF and QoL scales, but low-level FoF during use of public transport was linked to better QoL.

Hsu et $\mathrm{al}^{43}$ demonstrated a mediating effect of physical activity (PA) participation and the self-concept of health and physical independence on the relationship between FOF and QoL with lower PA levels being associated with higher FoF and reduced QoL in two independent samples in Germany and Taiwan.

\section{Does the association depend on the operationalization of FoF or QoL?}

The relevance of FoF for QoL appeared to be independent of the FoF instruments used as evidenced by the consistent results of the association across studies that administered different instruments. Few studies administered more than one instrument related to the FoF construct. The SAFE explained a comparable amount of variance in QoL (SF-36, 1-item question SRH) as the FES and a single question measurement of FoF (four levels). ${ }^{4}$ Contrary, Valentine et al applied the Caflik as a measure for fear of falling and the Confbal for balance confidence and both tools were parts of different paths in structural equation models. ${ }^{45}$

Most studies administered the SF-36, an abbreviated version of this instrument, SRH questions or the EQ-5D to assess QoL and nearly in all of these studies a significant association was demonstrated. The WHOQOL-BREF ${ }^{31}$ and mod WHOQOL-OLD, ${ }^{54}$ administered each in one study, did not show an overall association with FoF in Asian samples, although latter found a reduced level of QoL during public transport use and FoF. The use of the PGMS also demonstrated no association with FoF. ${ }^{45}$ Two studies administered more than one instrument of QoL. Tiernan et $\mathrm{al}^{52}$ found in multivariate logistic regression analyses that FoF (adapted FES) was a significant contributor to SRH and well-being (SPF-IL). However, the amount of variance explained was larger for $\mathrm{SRH}^{52}$ Another study found that older women with a falls history who were moderately or highly concerned about falls
(FES-I) reported poorer QoL (LEIPAD) and well-being (WHO-5) than those with low levels of concern. ${ }^{50}$ Due to the very wide confidence intervals, a direct comparison could not be done.

\section{Is there a mediating effect of falls on the association between FoF and QoL?}

To explore the potential mediating effect of actual fall events on the association of FoF and QoL, we looked at studies that used multivariate modeling and included all three variables. Several studies found FoF and falls to be independent predictors of QoL. ${ }^{4,15,39}$ Findings in studies with community-dwelling older people, including those from large epidemiological studies, however, indicated that FoF was a significant risk factor for reduced QoL after controlling for falls or fall-related injuries with little or no mediation from actual falls. $^{32,41,44,52}$ Iglesias and colleagues found that the main burden of QoL loss was FoF which was consistently associated with this outcome in three large datasets, while falls and fractures had much smaller effect sizes, with fall events being non-significant in two of these three studies. ${ }^{32}$ Similarly, Tiernan et al found that when including falls-efficacy and falls into the modeling process, latter added very little to the relationship with SRH beyond that explained by falls-efficacy. ${ }^{52}$ Contrary, FoF and falls were maintained independent predictors for well-being. ${ }^{52}$ Finally, Lin and colleagues demonstrated that among other factors, FoF was an independent predictor for overall QoL while fall events were not in community-dwelling elderly with functional limitations. ${ }^{44}$ Regarding individual domains of QoL these authors found both, FoF and falls were associated with self-care but only FoF was linked to mobility. ${ }^{44}$ In another study, fall history and FoF were associated with the physical function component of the SF-36 but only FoF was also associated with the mental function component. $^{41}$

Two of the identified studies were conducted in institutionalized settings. ${ }^{35,45}$ Kato found no mediating influence of falls on the relationship between falls-efficacy and the physical function component of the SF-8 in female nursing home residents. ${ }^{35}$ The study by Valentine and colleagues using structural equation modeling found no direct or indirect effect of falls, balance confidence, and falls-efficacy on the relationship between instability and QoL. ${ }^{45}$ 


\section{Discussion}

This systematic review aimed at determining the impact of FoF on QoL in older adults and the effect of actual fall events on this relationship. We found that FoF was consistently and strongly associated with QoL and this association appeared to be independent of the conceptualizations of FoF and QoL. Moreover, this relationship is independent of falls people experienced which seem to have a lower impact.

\section{What is the effect of FoF on QoL?}

Our results demonstrate a robust association of lower levels of FoF and higher perceived QoL. In multivariate analyses of single studies, FoF remained an independent predictor of QoL. Furthermore, the relationship appears to be more important than other basic variables such as age and gender. ${ }^{4,51}$

Fear is an important emotional trait that evolved and triggers innate responses important for survival and one of these fears is the fear of heights or depth which may lead to a fall with serious if not fatal consequences. ${ }^{58}$ How the concept of FoF in older adults fits in this context is less well established. But it seems that fearful individuals elicit postural responses in everyday activities that younger fearful people demonstrate when exposed to heights $>3 \mathrm{~m} .{ }^{59}$ Thus, emotion and balance control are associated with each other and more fearful people seem to learn associations between specifically related tasks and an avoidance response. ${ }^{60}$ While an activity avoidance may protect from dangerous situations and can already be observed in infants, ${ }^{61}$ it may be maladaptive if it exceeds a certain level, and thereby, the fear becomes debilitating, initiating a vicious cycle of activity reduction and physical and mental decline. ${ }^{62}$ In line with this, Hsu et $\mathrm{al}^{43}$ found a mediating effect of PA on the relationship between FoF and QoL.

While fear itself is a psychological construct, highest correlations were found not for mental but for physical components of QoL. ${ }^{4,33,35,46,49,52}$ Particularly strong associations with FoF were found for physical function, general health perceptions, bodily pain status, vitality, physical role functioning, and physical mobility, ${ }^{4,15,33,35,40,56}$ indicating that physical components of health are key determinants for high QoL. This is confirmed by findings that QoL is lower in people with medical conditions that affect physical functioning, including multimorbid and frail individuals ${ }^{63}$ while FoF is increased in physically frail older adults. ${ }^{64}$

It seems that the association between these physical limitations and FoF is in parts due to restricting activity participation and subsequent negative consequences. Similarly, one study in people with chronic musculoskeletal pain found that activity restriction due to FoF was associated with sedentary behavior. ${ }^{65}$ Howland and colleagues found the influence of FOF on activity restriction to be independent after controlling for other factors such as age, sex, pain, selfrated health, previous falls, medications, and the use of walking aids. ${ }^{39}$ This finding supports other results which stated that FOF is a significant predictor of activity restriction and that individuals being fearful were distinguished from those that additionally restricted their activities. ${ }^{14,66}$

Findings also indicate that activity restriction is related not only to physical functioning but also to psychological issues, such as depression. ${ }^{67,68}$ Individual studies found associations between mental health, social functioning and QoL, ${ }^{4,56}$ emphasizing that QoL is a complex multifactorial construct. This association may be linked to a maladaptive degree of activity restriction too. Fear only has positive effects as long as social and physical mobility is not decreased. ${ }^{69}$ Also, less social interaction, participation and becoming homebound can cause not only physical but also mental problems, resulting in reduced levels of QoL. ${ }^{70}$

The limitation of physical functions and reduction of social activities can lead to mental problems such as depression and loss of self-confidence. Self-critical thinking, low functional performance, and limited personal and social activities are risk or exacerbating factors for depressive symptoms in older people. ${ }^{71}$ Taking the physical and mental components together, activity restriction in older people can lead to deconditioning, depression, social isolation and thus reduced QoL. ${ }^{72}$ Hence, activity restriction appears to be an important link between FoF and QoL. Today it remains unclear, when and how individuals decide to avoid certain activities. A small qualitative study in people with FoF found that some individuals' QoL were not affected by their FoF while in others it led to restrictions of activities. ${ }^{73}$ It seems that this complex process involves physical and cognitive functions, rating one's own risk and subsequent risk-taking behavior and is influenced by personality traits (especially introversion/ extroversion), depressive symptoms among other factors. ${ }^{36,74-76}$ Anxious people may overestimate their actual risk of falling and subsequently avoid activities. ${ }^{74}$

Evidence suggests a direct link of FoF related measures on physical performance, such as balance and gait. ${ }^{77}$ Thus, QoL likely is also diminished by reduced physical functioning not related to activity restriction. In addition, recent fall experience has been associated with post-traumatic stress disorder in older 
people. ${ }^{78}$ Also, anxiety has been associated with chronic stress and the perseverative cognitive representation leads to elevated stress levels. ${ }^{79}$ As people are permanently concerned about falling, inflammation levels may be increased affecting one's physical and mental health. ${ }^{80-82}$ To our knowledge, no study has been published on this topic with regard to FoF but it might be another path how QoL is reduced by FoF.

\section{Does the association depend on the operationalization of FoF or QoL?}

No obvious systematic difference on the relationship of FoF and QoL in dependence of measurement method of FoF was found. A lower degree of FoF was consistently associated with better perceived QoL, independent of the instrument used for FoF and QoL. The majority of studies administered measures for falls-efficacy, the SAFE or 1-item questions for FoF and versions of the MOS questionnaire or 1-item SRH questions for QoL. Administering more than one instrument led to results pointing into the same direction, ${ }^{39,50,52,53}$ indicating that the underlying association was similar. Psychometric properties of multi-item generic measures of QoL and FoF measures have been questioned, ${ }^{83,84}$ but most of the ones used in the analyses were judged to be valid, internally consistent and reliable. Some QoL instruments were not associated with FoF but were each only administered in one study (WHOQOL-BREF, ${ }^{31} \bmod$ WHOQOL-OLD, ${ }^{54}$ PGMS $^{45}$ ). This may be caused by the different operationalization of QoL or sample characteristics and more studies are needed to draw firm conclusions.

While direct measurement of FoF and instruments of fallsefficacy were used, the latter construct has been criticized, as it is possible that people are confident of their abilities to engage in activities but may still be fearful of having a fall. ${ }^{69}$ Similarly, Hadjistavropoulos, Delbaere, and Fitzgerald argue that these constructs are not be used interchangeably as often done. ${ }^{77}$ Supporting this, the study by Valentine found no association between the constructs of self-efficacy, FoF and QoL using structural equation modeling. ${ }^{45}$ However, these authors applied different (newly developed) instruments that require further external validation. The authors point out that FoF in older adults is a multifactorial construct that is related to postural stability and lesser to general anxiety. ${ }^{45}$ Future studies of sufficient size are needed to determine the more complex relationships between concepts involved. There is limited evidence that suggests a difference in people that are concerned about falling and those that additionally restrict their activities. ${ }^{14}$ These groups are likely affected differently in their QoL. This relationship requires further investigation.

There is a need for further validation of FoF instruments potentially conceptualizing different constructs. For instance, brain networks including sub-cortical (low road) and higher cortical centers (high road) have been described as pathways in the processing of fear. ${ }^{85}$ However, sufficient data to show in how far FoF is associated to these are lacking.

\section{Is there a mediating effect of falls on the association between FoF and QoL?}

The majority of studies that included actual fall events as variable in the association between FoF or QoL found both, FoF and falls to be independent predictor of QoL or QoL and falls for FoF. All three concepts have been shown to be influenced not only by each other but also by multiple other factors. The fact that non-fallers may also be concerned about falls also indicates the independence of these measures. ${ }^{2}$ Falls and FoF independently predict each other and individuals, who have one of them, also have an increased risk to develop the other outcome. ${ }^{86}$ It has been shown that this fear declines linearly over time and becomes non-significant after two to three years without falling. ${ }^{87}$ However, it appears that in about $60 \%$ of the individuals $\mathrm{FoF}$ is persistent, with previous falls and female gender being independent risk factors. ${ }^{88}$ This may indicate different coping strategies that lead to the misperception of fall risk in some individuals ${ }^{74}$ and may further confirm the detrimental effect of persistent cognitions. Apart from being independent predictors of QoL, samples without heightened fall risk (eg, use of mobility aids, falls in the recent past) had the lowest levels of FoF. Higher prevalence of $\mathrm{FoF}$ was found in study populations with poorer general condition, with higher proportions of frail people or with heightened fall risk. Mentioned attributes were already identified as risk factors for FoF in a literature review. ${ }^{2}$ This demonstrates that FoF and falls also share some variance.

However, some studies demonstrated that fall events played no or a minor role in the association of FoF and QoL. ${ }^{32,35,41,44,52}$ FoF is associated with psychological factors (eg, depression) and physical function which in turn are known risk factors for falls in the elderly. ${ }^{89}$ Murphy, Dubin, \& Gill demonstrated that falls were only associated with FoF when other predisposing factors were present. ${ }^{90}$ 
It may be that instead of a direct relationship of falls, other with falls associated factors mediate the relationship between FoF and QoL, such as functional performance measures (instability, mobility). ${ }^{44,45}$ Recently, the simplistic vicious cycle in which fear leads to restriction of activities, deconditioning and increased risk of falls has been questioned. ${ }^{77}$ An alternative model in which FoF affects falls-efficacy which in turn affects balance performance negatively leading to an increased fall risk has been proposed. ${ }^{77}$ However, the multiple causes of falls are still not untangled and quite likely both paths play a role in the genesis of falls. In addition, it has been demonstrated that the level of PA mediates the relationship between FoF and outdoor falls. ${ }^{13}$ Low PA levels could be a proxy for activity restriction. As most studies did not obtain this measure, current evidence might underestimate the direct impact of fall-related activity restriction on the association between FoF and QoL. Future studies are required to determine more complex and accurate cause-effect models.

\section{Clinical implications}

Findings of this review demonstrate the importance of FoF on QoL and thus on the subjectively perceived well-being of an individual. Hence, the identification of individuals at risk and the subsequent intervention to reduce FoF are important to increase QoL in older people. FoF and associated factors are modifiable risk factors and should be targeted in clinical interventions to improve QoL as important patient-centered outcome. The relationship between FoF and QoL appears to be partially mediated by physical and cognitive functioning and by higher levels of PA. Increased PA levels and in particular structured exercise have been linked to improve physical $^{91}$ and cognitive functioning, ${ }^{92}$ reduced levels of FoF, ${ }^{93}$ and increased QoL. ${ }^{94}$

Also, cognitive-behavioral interventions that can be administered at home and aim at cognitive re-structuring to instill adaptive and realistic views are effective in reducing FoF and related activity restriction in older adults, ${ }^{95}$ partially mediated by psychosocial factors such as control beliefs, self-efficacy, and outcome expectations. ${ }^{96}$

\section{Limitations of the review}

We acknowledge several limitations of this review. First, only English language and full articles were included. Therefore, it is possible that relevant studies not fulfilling these criteria were excluded. Second, some articles were excluded due to populations with specific diseases. While included studies often did not exclude individuals with specific conditions or multimorbidity, the generalizability of results may be limited. Third, different scales and instruments were used to conceptualize the constructs of FoF and QoL. Although these might not measure exactly the same, our results were quite similar and did not appear to be influenced by the underlying differences. Finally, we did not investigate the effect of specific or non-specific interventions on the relationship between FoF and QoL. To our knowledge, there has been no systematic review published on this topic.

\section{Conclusions}

Findings of this systematic review demonstrate the importance of fear of falling on quality of life in older individuals which is independent of fall events and appears to be more important than actual falls. This association also seems to be independent of different conceptualizations of FoF. Clinically, this implies FoF should be considered not only as by-product of falls and requires targeted interventions, different from those aiming to reduce falls. More research is needed to prospectively investigate the cause-effect relationship of FoF, falls and QoL, determine the validity of different constructs involved, and to investigate whether specific activities are linked stronger to QoL than others.

\section{Disclosure}

The authors report no conflicts of interest in this work.

\section{References}

1. Aoyagi K, Ross PD, Davis JW, Wasnich RD, Hayashi T, Takemoto T-I. Falls among community-dwelling elderly in Japan. $J$ Bone Miner Res. 1998;13(9):1468-1474. doi:10.1359/ jbmr.1998.13.9.1468

2. Scheffer AC, Schuurmans MJ, van Dijk N, van der Hooft T, de Rooij SE. Fear of falling: measurement strategy, prevalence, risk factors and consequences among older persons. Age Ageing. 2008;37 (1):19-24. doi:10.1093/ageing/afm 169

3. Murphy J, Isaacs B. The post-fall syndrome. A study of 36 elderly patients. Gerontology. 1982;28(4):265-270. doi:10.1159/000212543

4. Lachman ME, Howland J, Tennstedt S, Jette A, Assmann S, Peterson EW. Fear of falling and activity restriction: the survey of activities and fear of falling in the elderly (SAFE). J Gerontol B Psychol Sci Soc Sci. 1998;53(1): P43-50. doi:10.1093/geronb/53B.1.P43

5. Lawrence RH, Tennstedt SL, Kasten LE, Shih J, Howland J, Jette AM. Intensity and correlates of fear of falling and hurting oneself in the next year: baseline findings from a Roybal center fear of falling intervention. J Aging Health. 1998;10(3):267-286. doi:10.1177/ 089826439801000301

6. Legters K. Fear of falling. Phys Ther. 2002;82(3):264-272.

7. Myers AM, Powell LE, Maki BE, Holliday PJ, Brawley LR, Sherk W. Psychological indicators of balance confidence: relationship to actual and perceived abilities. J Gerontol A Biol Sci Med Sci. 1996;51(1): M37-43. doi:10.1093/gerona/51A.1.M37 
8. Bandura A. Self-efficacy: toward a unifying theory of behavioral change. Psychol Rev. 1977;84(2):191-215. doi:10.1037/0033-295X.84.2.191

9. Tinetti ME, Richman D, Powell L. Falls efficacy as a measure of fear of falling. $J$ Gerontol. 1990;45(6):P239-243.

10. Powell LE, Myers AM. The Activities-specific Balance Confidence (ABC) scale. J Gerontol A Biol Sci Med Sci. 1995;50a(1):M28-34.

11. Vellas BJ, Wayne SJ, Romero LJ, Baumgartner RN, Garry PJ. Fear of falling and restriction of mobility in elderly fallers. Age Ageing. 1997;26(3):189-193. doi:10.1093/ageing/26.3.189

12. Donoghue OA, Cronin H, Savva GM, O'Regan C, Kenny RA. Effects of fear of falling and activity restriction on normal and dual task walking in community dwelling older adults. Gait Posture. 2013;38(1):120-124. doi:10.1016/j.gaitpost.2012.10.023

13. Wijlhuizen GJ, de Jong R, Hopman-Rock M. Older persons afraid of falling reduce physical activity to prevent outdoor falls. Prev Med. 2007;44(3):260-264. doi:10.1016/j.ypmed.2006.11.003

14. Murphy SL, Williams CS, Gill TM. Characteristics associated with fear of falling and activity restriction in community-living older persons. J Am Geriatr Soc. 2002;50(3):516-520.

15. Arfken CL, Lach HW, Birge SJ, Miller JP. The prevalence and correlates of fear of falling in elderly persons living in the community. Am J Public Health. 1994;84(4):565-570.

16. Elliott MS, Barris R. Occupational role performance and life satisfaction in elderly persons. Occup Ther J Res. 1987;7(4):215-224 doi: $10.1177 / 153944928700700403$

17. Levasseur M, Desrosiers J, Noreau L. Is social participation associated with quality of life of older adults with physical disabilities? Disabil Rehabil. 2004;26(20):1206-1213. doi:10.1080/09638280412331270371

18. Gerok W, Brandstädter J. Normales, krankhaftes und optimales altern: variations- und Modifikationsspielräume. In: Baltes PB, Mittelstraß J, Staudinger UM, editors. Alter und Altern: Ein interdisziplinärer Studientext zur Gerontologie. Berlin: de Gruyter; 1994:356-386.

19. Halvorsrud L, Kalfoss M. The conceptualization and measurement of quality of life in older adults: a review of empirical studies published during 1994-2006. Eur J Ageing. 2007;4(4):229-246. doi:10.1007/ s10433-007-0063-3

20. Bowling A. Measuring Disease, second edition. Philadelphia: Open University Press; 2001.

21. Noro A, Aro S. Health-related quality of life among the least dependent institutional elderly compared with the non-institutional elderly population. Qual Life Res. 1996;5(3):355-366. doi:10.1007/BF00433920

22. Bakas T, McLennon SM, Carpenter JS, et al. Systematic review of health-related quality of life models. Health Qual Life Outcomes. 2012;10(1):134. doi:10.1186/1477-7525-10-134

23. Romero M, Vivas-Consuelo D, Alvis-Guzman N. Is Health Related Quality of Life (HRQoL) a valid indicator for health systems evaluation? SpringerPlus. 2013;2(1):664. doi:10.1186/2193-1801-2-664

24. de Wit M, Hajos T. Health-related quality of life. In: Gellman MD, Turner JR, editors. Encyclopedia of Behavioral Medicine. New York: Springer New York; 2013:929-931.

25. Organization WH. Good Health Adds Life to Years: Global Brief for World Health Day 2012. Geneva: WHO; 2012.

26. Deshpande PR, Rajan S, Sudeepthi BL, Abdul Nazir CP. Patientreported outcomes: A new era in clinical research. Perspect Clin Res 2011;2(4):137-144. doi:10.4103/2229-3485.86879

27. NICE. Multimorbidity: clinical assessment and management. NICE guideline [NG56]; 2016. Available from: https://www.nice.org.uk/ guidance/ng56/resources/multimorbidity-clinical-assessment-andmanagement-pdf-1837516654789. Accessed November 28, 2018.

28. Yarnall AJ, Sayer AA, Clegg A, Rockwood K, Parker S, Hindle JV. New horizons in multimorbidity in older adults. Age Ageing. 2017;46 (6):882-888. doi:10.1093/ageing/afx 150

29. National Heart, Lung, and Blood Institute. Quality Assessment Tool for Observational Cohort and Cross-Sectional Studies. Bethesda: National Institutes of Health, Department of Health and Human Services; 2014.
30. Davis JC, Marra CA, Liu-Ambrose TY. Falls-related self-efficacy is independently associated with quality-adjusted life years in older women. Age Ageing. 2011;40(3):340-346. doi:10.1093/ageing/afr019

31. Basalan IF, Atay E. How effective are exercise recommendations supported by written and visual materials in elderly people? Turk Geriatri Dergisi. 2014;17(4):410-416.

32. Iglesias CP, Manca A, Torgerson DJ. The health-related quality of life and cost implications of falls in elderly women. Osteoporos Int. 2009;20(6):869-878. doi:10.1007/s00198-008-0753-5

33. Warnke A, Meyer G, Bott U, Mühlhauser I, Validation of a quality of life questionnaire measuring the subjective fear of falling in nursing home residents. Z Gerontol Geriatr. 2004;37(6):459-466. Available from: http://onlinelibrary.wiley.com/o/cochrane/clcentral/articles/419/ CN-00511419/frame.html. doi:10.1007/s00391-004-0214-5

34. Yeung FKC, Chou KL, Wong ECH. Characteristics associated with fear of falling in Hong Kong Chinese elderly residing in care and attention homes. Clin Gerontol. 2006;29(3):83-98. doi:10.1300/ J018v29n03 07

35. Kato C, Ida K, Kawamura M, et al. Relation of falls efficacy scale (FES) to quality of life among nursing home female residents with comparatively intact cognitive function in Japan. Nagoya J Med Sci. 2008;70(1-2):19-27.

36. Kloseck M, Hobson S, Crilly R, Vandervoort A, Ward-Griffin C. The influence of personality on falling and engagement in daily activities by community-dwelling older adults. Phys Occup Ther Geriatr. 2007;26(1):1-17. doi:10.1080/J148v26n01_01

37. Cinarli T, Koc Z. Fear and risk of falling, activities of daily living, and quality of life: assessment when older adults receive emergency department care. Nurs Res. 2017;66(4):330-335. doi:10.1097/ NNR.0000000000000227

38. Suzuki M, Ohyama N, Yamada K, Kanamori M. The relationship between fear of falling, activities of daily living and quality of life among elderly individuals. Nurs Health Sci. 2002;4(4):155-161. doi:10.1046/j.1442-2018.2002.00123.x

39. Howland J, Peterson EW, Levin WC, Fried L, Pordon D, Bak S. Fear of falling among the community-dwelling elderly. J Aging Health. 1993;5(2):229-243. doi:10.1177/089826439300500205

40. Akosile CO, Anukam GO, Johnson OE, et al. Fear of falling and quality of life of apparently-healthy elderly individuals from a nigerian population. J Cross Cult Gerontol. 2014;29(2):201-209. doi:10.1007/s10823-014-9228-7

41. Chang N, Chi L, Yang N, Chou P. The impact of falls and fear of falling on health-related quality of life in Taiwanese elderly. $J$ Community Health Nurs. 2010;27(2):84-95. doi:10.1080/07370011003704958

42. Chang N, Yang N, Chou P. Incidence, risk factors and consequences of falling injuries among the community-dwelling elderly in Shihpai, Taiwan. Aging Clin Exp Res. 2010;22(1):70-77. doi:10.1007/ BF03324818

43. Hsu Y, Alfermann D, Lu FJH, Lin LL. Pathways from fear of falling to quality of life: the mediating effect of the self-concept of health and physical independence. Aging Ment Health. 2013;17(7):816-822. doi:10.1080/13607863.2013.805398

44. Lin SI, Chang KC, Lee HC, Yang YC, Tsauo JY. Problems and fall risk determinants of quality of life in older adults with increased risk of falling. Geriatr Gerontol Int. 2015;15(5):579-587. doi:10.1111/ggi.12320

45. Valentine JD, Simpson J, Worsfold C, Fisher K. A structural equation modelling approach to the complex path from postural stability to morale in elderly people with fear of falling. Disabil Rehabil. 2011;33(4):352-359. doi:10.3109/09638288.2010.491575

46. Chang HT, Chen HC, Chou P. Factors associated with fear of falling among community-dwelling older adults in the Shih-Pai study in Taiwan. PLoS One. 2016;11(3):e0150612. doi:10.1371/journal. pone. 0150612

47. Liu JY. Fear of falling in robust community-dwelling older people: results of a cross-sectional study. J Clin Nurs. 2015;24(3-4):393-405. doi:10.1111/jocn.2015.24.issue-3pt4 
48. Malini FM, Lourenco RA, Lopes CS. Prevalence of fear of falling in older adults, and its associations with clinical, functional and psychosocial factors: the frailty in Brazilian older people-Rio de Janeiro study. Geriatr Gerontol Int. 2016;16(3):336-344. doi:10.1111/ggi.12477

49. Li F, Fisher KJ, Harmer P, McAuley E, Wilson NL. Fear of falling in elderly persons: association with falls, functional ability, and quality of life. J Gerontol B Psychol Sci Soc Sci. 2003;58(5):P283-290. doi:10.1093/geronb/58.5.P283

50. Patil R, Uusi-Rasi K, Kannus P, Karinkanta S, Sievanen H. Concern about falling in older women with a history of falls: associations with health, functional ability, physical activity and quality of life. Gerontology. 2014;60(1):22-30. doi:10.1159/000354335

51. Stretton CM, Latham NK, Carter KN, Lee AC, Anderson CS. Determinants of physical health in frail older people: the importance of self-efficacy. Clin Rehabil. 2006;20(4):357-366. doi:10.1191/ 0269215506cr946oa

52. Tiernan C, Lysack C, Neufeld S, Goldberg A, Lichtenberg PA. Falls efficacy and self-rated health in older African American adults. Arch Gerontol Geriatr. 2014;58(1):88-94. doi:10.1016/j.archger.2013. 08.005

53. Baharlouei H, Salavati M, Akhbari B, Mosallanezhad Z, Mazaheri M, Negahban H. Cross-cultural validation of the Falls Efficacy Scale International (FES-I) using self-report and interview-based questionnaires among Persian-speaking elderly adults. Arch Gerontol Geriatr. 2013;57(3):339-344. doi:10.1016/j.archger.2013.06.005

54. Yodmai K, Phummarak S, Sirisuth JC, Kumar R, Somrongthong R. Quality of life and fear of falling among an aging population in semi rural, Thailand. J Ayub Med Coll Abbottabad. 2015;27(4):771-774.

55. Hoang OT, Jullamate P, Piphatvanitcha N, Rosenberg E. Factors related to fear of falling among community-dwelling older adults. $J$ Clin Nurs. 2017;26(1-2):68-76. doi:10.1111/jocn.13337

56. Billis E, Strimpakos N, Kapreli E, et al. Cross-cultural validation of the Falls Efficacy Scale International (FES-I) in Greek community-dwelling older adults. Disabil Rehabil. 2011;33(19-20):1776-1784. doi:10.3109/09638288.2010.546937

57. Stubbs B, Schofield P, Patchay S, Leveille S. Musculoskeletal pain characteristics associated with lower balance confidence in community-dwelling older adults. Physiother. 2016;102(2):152-158. doi:10.1016/j.physio.2015.03.3721

58. Ohman A, Mineka S. Fears, phobias, and preparedness: toward an evolved module of fear and fear learning. Psychol Rev. 2001;108 (3):483-522. doi:10.1037/0033-295X.108.3.483

59. Davis JR, Campbell AD, Adkin AL, Carpenter MG. The relationship between fear of falling and human postural control. Gait Posture. 2009;29(2):275-279. doi:10.1016/j.gaitpost.2008.09.006

60. Tinetti ME, Powell L. Fear of falling and low self-efficacy: a case of dependence in elderly persons. J Gerontol. 1993;48:Spec No:35-38. doi:10.1093/geronj/48.Special_Issue.35

61. Gibson EJ, Walk RD. The "visual cliff.". Sci Am. 1960;202(4):64-71. doi:10.1038/scientificamerican0460-64

62. Cumming RG, Salkeld G, Thomas M, Szonyi G. Prospective study of the impact of fear of falling on activities of daily living, SF-36 scores, and nursing home admission. J Gerontol A Biol Sci Med Sci. 2000;55 (5):M299-305. doi:10.1093/gerona/55.5.M299

63. Li CI, Lin CH, Lin WY, et al. Successful aging defined by health-related quality of life and its determinants in community-dwelling elders. BMC Public Health. 2014;14:1013. doi:10.1186/1471-2458-14-1013

64. Esbri-Victor M, Huedo-Rodenas I, Lopez-Utiel M, et al. Frailty and fear of falling: the FISTAC study. J Frailty Aging. 2017;6 (3):136-140.

65. Stubbs B, Patchay S, Soundy A, Schofield P. The avoidance of activities due to fear of falling contributes to sedentary behavior among community-dwelling older adults with chronic musculoskeletal pain: a multisite observational study. Pain Med. 2014;15 (11):1861-1871. doi:10.1111/pme.12570
66. Fletcher PC, Guthrie DM, Berg K, Hirdes JP. Risk factors for restriction in activity associated with fear of falling among seniors within the community. J Patient Saf. 2010;6(3):187-191. doi:10.1097/ PTS.0b013e3181f1251c

67. Boltz M, Resnick B, Capezuti E, Shuluk J. Activity restriction vs. selfdirection: hospitalised older adults' response to fear of falling. Int J Older People Nurs. 2014;9(1):44-53. doi:10.1111/opn.2014.9.issue-1

68. Mausbach BT, Chattillion EA, Moore RC, Roepke SK, Depp CA, Roesch S. Activity restriction and depression in medical patients and their caregivers: a meta analysis. Clin Psychol Rev. 2011;31 (6):900-908. doi:10.1016/j.cpr.2011.04.004

69. Jung D. Fear of falling in older adults: comprehensive review. Asian Nurs Res (Korean Soc Nurs Sci). 2008;2(4):214-222. doi:10.1016/ S1976-1317(09)60003-7

70. Painter JA, Allison L, Dhingra P, Daughtery J, Cogdill K, Trujillo LG. Fear of falling and its relationship with anxiety, depression, and activity engagement among community-dwelling older adults. Am J Occup Ther. 2012;66(2):169-176. doi:10.5014/ajot.2012.002535

71. Fiske A, Wetherell JL, Gatz M. Depression in older adults. Annu Rev Clin Psychol. 2009;5:363-389. doi:10.1146/annurev. clinpsy.032408.153621

72. Vlaeyen JW, Linton SJ. Fear-avoidance and its consequences in chronic musculoskeletal pain: a state of the art. Pain. 2000;85 (3):317-332. doi:10.1016/S0304-3959(99)00242-0

73. Tischler L, Hobson S. Fear of falling: a qualitative study among community-dwelling older adults. Phys Occup Ther Geriatr. 2005;23(4):37-53. doi:10.1080/J148v23n04_03

74. Delbaere K, Close JC, Brodaty H, Sachdev P, Lord SR. Determinants of disparities between perceived and physiological risk of falling among elderly people: cohort study. BMJ. 2010;341:c4165. doi:10.1136/bmj.c4165

75. Butler AA, Lord SR, Taylor JL, Fitzpatrick RC. Ability versus hazard: risk-taking and falls in older people. J Gerontol A Biol Sci Med Sci. 2015;70(5):628-634. doi:10.1093/gerona/glu201

76. Butler AA, Lord SR, Fitzpatrick RC. Perceptions of speed and risk: experimental studies of road crossing by older people. PLoS One. 2016;11(4):e0152617. doi:10.1371/journal.pone.0152617

77. Hadjistavropoulos T, Delbaere K, Fitzgerald TD. Reconceptualizing the role of fear of falling and balance confidence in fall risk. $J$ Aging Health. 2011;23(1):3-23. doi:10.1177/0898264310378039

78. Bloch F. Literature review and meta-analysis of risk factors for delayed post-traumatic stress disorder in older adults after a fall. Int J Geriatr Psychiatry. 2017;32(2):136-140. doi:10.1002/gps. v32.2

79. Brosschot JF. Markers of chronic stress: prolonged physiological activation and (un)conscious perseverative cognition. Neurosci Biobehav Rev. 2010;35(1):46-50. doi:10.1016/j.neubiorev.2010.01.004

80. Vogelzangs N, Beekman ATF, de Jonge P, Penninx BWJH. Anxiety disorders and inflammation in a large adult cohort. Transl Psychiatry. 2013;3(4):e249. doi:10.1038/tp.2013.27

81. Miller GE, Blackwell E. Turning up the heat:inflammation as a mechanism linking chronic stress, depression, and heart disease. Curr Dir Psychol Sci. 2006;15(6):269-272. doi:10.1111/j.14678721.2006.00450.x

82. Korte SM. Corticosteroids in relation to fear, anxiety and psychopathology. Neurosci Behav Rev. 2001;25(2):117-142. doi:10.1016/S0149-7634(01)00002-1

83. Haywood KL, Garratt AM, Fitzpatrick R. Quality of life in older people: a structured review of generic self-assessed health instruments. Qual Life Res. 2005;14(7):1651-1668. doi:10.1007/s11136-005-1743-0

84. Denkinger MD, Lukas A, Nikolaus T, Hauer K. Factors associated with fear of falling and associated activity restriction in community-dwelling older adults: a systematic review. Am J Geriatr Psychiatry. 2015;23 (1):72-86. doi:10.1016/j.jagp.2014.03.002

85. LeDoux JE. The Emotional Brain: The Mysterious Underpinnings of Emotional Life. New York: Simon \& Schuster; 1996. 
86. Friedman SM, Munoz B, West SK, Rubin GS, Fried LP. Falls and fear of falling: which comes first? A longitudinal prediction model suggests strategies for primary and secondary prevention. $J \mathrm{Am}$ Geriatr Soc. 2002;50(8):1329-1335.

87. Jang SN, Cho SI, Oh SW, Lee ES, Baik HW. Time since falling and fear of falling among community-dwelling elderly. Int Psychogeriatr. 2007;19(6):1072-1083. doi:10.1017/ S1041610206004807

88. Oh-Park M, Xue X, Holtzer R, Verghese J. Transient versus persistent fear of falling in community-dwelling older adults: incidence and risk factors. J Am Geriatr Soc. 2011;59(7):1225-1231. doi:10.1111/ j.1532-5415.2011.03475.x

89. Deandrea S, Lucenteforte E, Bravi F, Foschi R, La Vecchia C, Negri E. Risk factors for falls in community-dwelling older people: a systematic review and meta-analysis. Epidemiology. 2010;21 (5):658-668. doi:10.1097/EDE.0b013e3181e9edc4

90. Murphy SL, Dubin JA, Gill TM. The development of fear of falling among community-living older women: predisposing factors and subsequent fall events. J Gerontol A Biol Sci Med Sci. 2003;58(10): M943-947. doi:10.1093/gerona/58.10.M943

91. Steib S, Schoene D, Pfeifer K. Dose-response relationship of resistance training in older adults: a meta-analysis. Med Sci Sports Exerc. 2010;42(5):902-914. doi:10.1249/MSS.0b013e3181c34465
92. Kelly ME, Loughrey D, Lawlor BA, Robertson IH, Walsh C, Brennan S. The impact of exercise on the cognitive functioning of healthy older adults: a systematic review and meta-analysis. Ageing Res Rev. 2014;16:12-31. doi:10.1016/j.arr.2014.05.002

93. Kendrick D, Kumar A, Carpenter H, et al. Exercise for reducing fear of falling in older people living in the community. Cochrane Database Syst Rev. 2014;(11):CD009848.

94. Rejeski WJ, Mihalko SL. Physical activity and quality of life in older adults. J Gerontol A Biol Sci Med Sci. 2001;56(suppl_2):23-35.

95. Dorresteijn TA, Zijlstra GA, Ambergen AW, Delbaere K, Vlaeyen JW, Kempen GI. Effectiveness of a home-based cognitive behavioral program to manage concerns about falls in community-dwelling, frail older people: results of a randomized controlled trial. BMC Geriatr. 2016;16:2. doi:10.1186/s12877-015-0177-y

96. Zijlstra GA, van Haastregt JC, van Eijk JT, de Witte LP, Ambergen T, Kempen GI. Mediating effects of psychosocial factors on concerns about falling and daily activity in a multicomponent cognitive behavioral group intervention. Aging Ment Health. 2011;15(1):68-77. doi:10.1080/13607863.2010.501054
Clinical Interventions in Aging

\section{Publish your work in this journal}

Clinical Interventions in Aging is an international, peer-reviewed journal focusing on evidence-based reports on the value or lack thereof of treatments intended to prevent or delay the onset of maladaptive correlates of aging in human beings. This journal is indexed on PubMed Central, MedLine, CAS, Scopus and the Elsevier

\section{Dovepress}

Bibliographic databases. The manuscript management system is completely online and includes a very quick and fair peer-review system, which is all easy to use. Visit http://www.dovepress.com/ testimonials.php to read real quotes from published authors. 